\title{
Towards Sustainable Livelihood Practices in the Indigenous Forests of Zambia's Central Province: Barriers and Opportunities
}

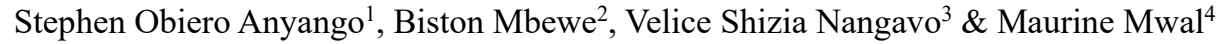 \\ ${ }^{1}$ Center for Advanced Studies in Environmental Law and Policy (CASELAP), University of Nairobi, PO Box \\ 30197, Nairobi, Kenya \\ ${ }^{2}$ Department of Forest, Ministry of lands and Natural Resources, The Government of the Republic of Zambia, \\ Kenya \\ ${ }^{3}$ UNDP Zambia Country Office, Kenya \\ ${ }^{4}$ Department of forest, Ministry of lands and Natural Resources, The Government of the Republic of Zambia, \\ Kenya \\ Correspondence: Stephen Obiero Anyango, Center for Advanced Studies in Environmental Law and Policy \\ (CASELAP), University of Nairobi, PO Box 30197, Nairobi, Kenya. E-mail: s.obieroanyango@gmail.com
}

Received: January 11, 2018

Accepted: February 16, 2018

Online Published: November 26, 2018

doi:10.5539/eer.v8n2p1

URL: https://doi.org/10.5539/eer.v8n2p1

\begin{abstract}
This study was designed with the aim of establishing a comprehensive picture of the problems and needs of local communities in upholding sustainable livelihoods in the face of forest degradation and recommending how their livelihoods may be improved in the short and long term. Thus make them self-reliant by enhancing their resilience. Study Methodology: included a literature review and a household survey for a total of 443 household interviews. In addition, Focus Group Discussions (FGDs) and Key Informant Interviews (KIIs) were conducted with the rural population and other stakeholders respectively. Field visits were made to all the 8 sites in the two districts Serenje and Chitambo. The main constrain of sustainable livelihood in the communities, included, low levels of education and skills, low levels of asset holding, weak local institutions and unfavorable legal and institutional frameworks. But the respondents registered a wide variety of NTFPs based livelihoods obtained from forests resources (15). Most important usage includes land for cultivation, fuelwood, poles for construction, charcoal production and use of NTFPs (collection of mushrooms, wild fruits and nuts, caterpillars, honey production and medicinal plants). The livelihood activities remains largely subsistence and for safety net functions. Trade resulting into incomes generation is minimal, unstructured and therefore unsustainable. In conclusion: commercialization of NTFPS and PES activities may be the solution to sustainable livelihood and forest conservation. A range of specifically forest sector elements would also need to be addressed, including, entrepreneurship, market and skill development for forest product and services delivery; embracing these elements will also require new kinds of enhanced institutional arrangement.
\end{abstract}

Keywords: sustainable livelihood, Forest resources, Zambia's Central Province

\section{Background}

Zambia's forested land cover comprises about $60 \%$ of her land mass of which; miombo woodland is the most extensive forest ecosystem in Zambia (Kalinda, et al., 2013, Campbell et al., 2008). The forest supports the livelihoods of rural and urban populations (Chirwa, et al., 2008). Unfortunately, the current forest utilization has resulted in continued deforestation, estimated at a rate of 250,000 to 300,000 hectares per year (Jayne, et al., 2014, GRZ, 2006). Spatially in central province the forest exists in both protected forest areas (20\%) and open areas on customary lands $(80 \%)$. And most of this deforestation occurs on customary lands where there is a tradition management regime in place thus mostly facilitating open access conditions (GRZ 2014). Central Province of Zambia has over the years experienced accelerated deforestation rates mainly due to fuelwood and charcoal production and agricultural expansion with little effort put into regeneration of the indigenous forests. Owing to its proximity to the Capital City Lusaka and other urban areas where fuelwood demand is highest.

The accelerated deforestation rate is exposing the rural communities to substantial vulnerability and risks, often the problems of poverty and forest degradation are intertwined, as observed elsewhere forest resources 
conservation may significantly be achieved if strategies are put in place to enhance the community's livelihood and diversification of local income streams (Kalinda, and Bwalya, 2014, Alexiades and Shanley, 2005). Thus decoupling community livelihoods from deforestation and making them more sustainable and resilient. Restoring forests, based on sustainable livelihood (SL) and environmental management (EM) measures may build resilience to the forest resources and lift economies and provide business opportunities.

The forest department was promoting climate-resilient and community-based regeneration of indigenous forests in Zambia's Central Province. The initiative was due to increased pressure on the forest resources in the project sites (Serenje and Chitambo districts), arising from well documented factors including: increased forest conversion for agriculture expansion and production of charcoal, improper use of anthropogenic induced forest fires as a management tool, thus affecting forest regeneration and at times resulting in complete degradation (tree mortality).

The initiative was established in eight project sites in the rural set ups of Serenje and Chitambo districts of Central province, where local community's livelihood is highly dependent on the forest resources. Lately, deteriorating natural capital base compounded with extreme weather events have been reported as having significant negative effect on the sustainability of the livelihoods of the rural population. This calls for an assessment of the community's coping and adaptation strategies. Thereby identify and propose sustainable livelihood practices for the communities and thereafter suggest mechanisms to supporting the recommended best practices suitable in the project areas. Poverty levels remain high in the project sites and the present patterns of utilization of the forest resources are unsustainable (Syampungani et al., 2009).

The overall goal of the study was "To increase the rate of forest regeneration and promote climate-resilient adaptation practices among forest-dependent communities in Zambia's Central Province. The objective of the project is to address twin challenges of REDD+ implementation for climate mitigation and enhance climate resilience of ecosystems and communities through diversification of ecosystem-based livelihoods using Assisted Natural Regeneration and Agroforestry, Integrated Fire Management and by addressing the current unsustainable utilization of biomass for charcoal by enhancing energy and resource use efficiency.

\subsection{Aim and Objectives of the Study}

The aim and objectives of the study included;

1. Undertake a comprehensive analysis and documentation of the current livelihood strategies of the communities in 8-pilot (in the two districts) sites using the sustainable livelihood framework.

2. Propose sustainable livelihood activities using the local knowledge.

3. Identify and recommend other sustainable livelihood practices that could be introduced in the project areas.

4. Propose a mechanism on supporting the recommended best practices.

The study focused on supporting the local communities by proposing practices that may make them self-reliant by enhancing their freedom and capacity to accelerate and participate in their development. Challenges faced by local communities in finding decent economic opportunities were discussed, because it was realized that communities were only likely to move away from unsustainable production methods, if sustainable livelihood options were provided. This requires that one tries out livelihood activities that will be proposed and implemented based on the land use resource maps of the 8 pilot sites. This study was designed with the overall aim of forming a comprehensive picture of the problems and needs of local people in maintaining sustainable livelihoods in the face of forest degradation, and recommending how their livelihoods may be improved in the short and long term.

\section{Approaches and Methodology}

\subsection{Approaches}

A comprehensive, mixed-methods approach, utilizing both qualitative and quantitative data types was employed. Besides the initial desk study, the assessment employed household survey interviews, Key informant interviews (KIIs) and participatory rural appraisal (PRA): where a wide range of PRA tools were used, including focus group discussions (FGDs), observations, calendar describing communities timeline activities and livelihood ranking exercises. This approach allowed the target stakeholders (rural farmers and the local project team) to have an active role in identifying and explaining the challenges they face, their strengths and opportunities, and what they most need to support them to address forest degradation and build more sustainable livelihoods. It was also intended to encourage these stakeholders to have a sense of ownership of the findings of the assessment and therefore be more likely to support and collaborate to implement the resulting project activities. 
Target groups were the rural population whose livelihoods were being assessed. Other important stakeholders were local government officials, from the two districts, in particular from relevant government departments including: the Forest department, Agriculture, Community development, Traditional Authorities and a local NGO (COMACO etc.).

\subsection{Study Sites}

The 8 Pilot sites in the 2 districts included: Mwimbula, London, Myenje, Musangashi, Teta, Nakatambo A, Nakatambo B, and Kampabwa see map below.

\section{Pilot Areas}
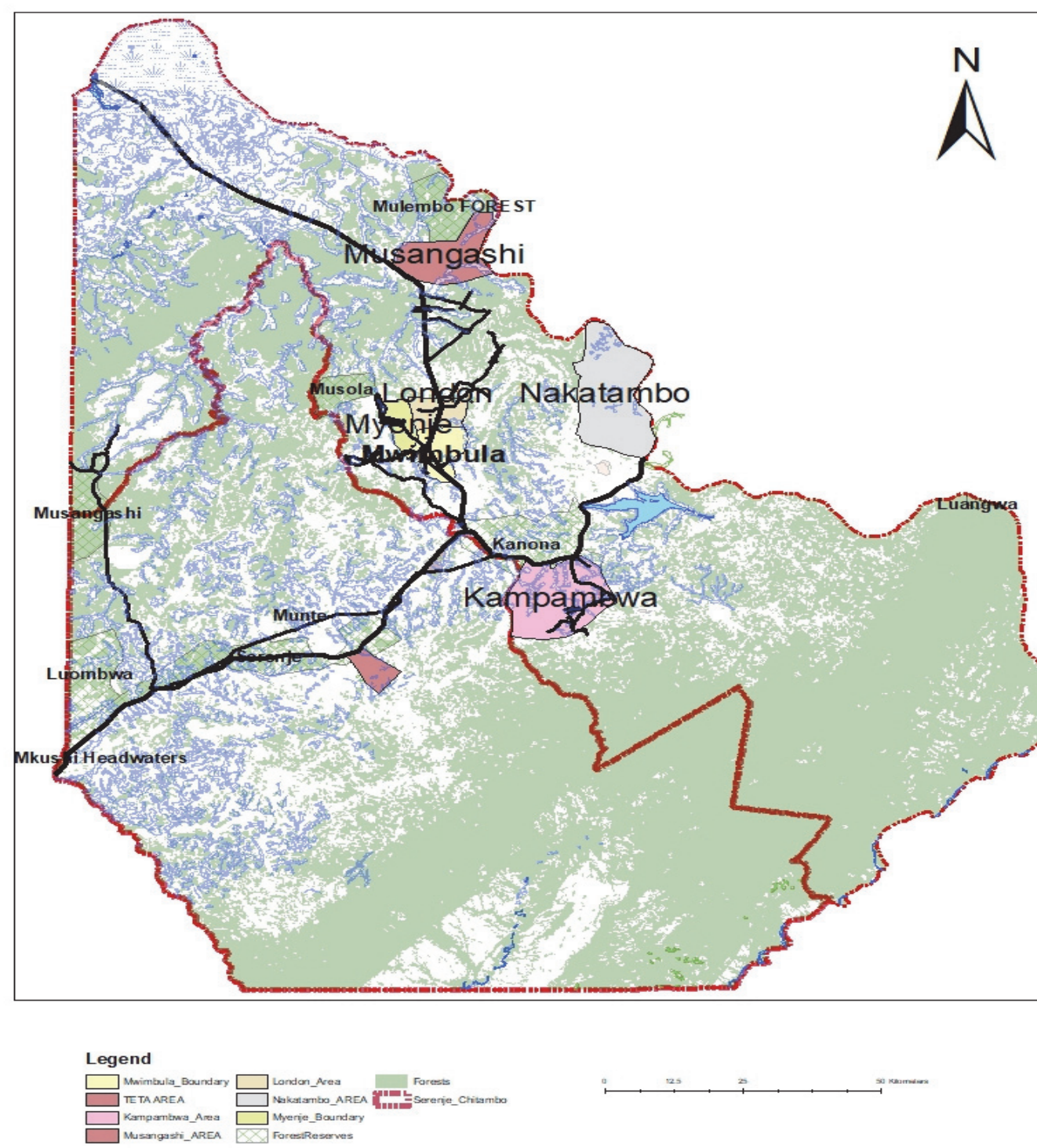

Plate 1. The 8 Pilot study Area

\subsection{Literature Review}

Relevant literature review was important in identifying products that could be used to illustrate the role of forests and forestry in livelihoods and to some extent the national economy, the notion of "sustainable livelihoods" provided a key approach to understanding livelihoods. According to the framework, household assets and entitlements were categorized into "five capitals" namely natural, physical, financial, human and social capital. 
Case studies and data from the Forestry department of Zambia including, Forest livelihood and economic survey (FLES) of the integrated land use assessment II: Data Collection Manual, Integrated land use Assessment (ILUA) Phase II (2011-2016) and Project reports.

A systematic process was followed in acquiring the required data.

\subsection{Household Survey}

An interviewer administered questionnaire was designed and used to conduct the household survey, which began with a training session for the Research Assistants (RAs) on administering of HH questionnaires, followed by pretesting. The questionnaires were administered using a smart phone based application Open Data Kit (ODK), which was installed in all the phones used by RAs. This ensured real time data collection and monitoring through a central server accessible to the consultant. The household survey conducted in September 2016 provided an overview of the rural livelihood in the study. A total of 443 households in eight project sites were randomly sampled but based on the Sampling frame adopted from FLES (GRZ, 2014). The villages surveyed in each of the sampled site were purposefully selected to capture the diversity of among the villages in the project area.

\subsection{Key Informant Interviews, Focused Group Discussions and Observations}

In-depth semi-structured Interviews including Focus Group Discussions (FGDs) and Key Informant Interviews (KIIs) were undertaken with various stakeholders. Field visits were made in all the projects sites to make observations on the projects visible scenarios. All the FGDs and KIIs were done by the consultant assisted by an interpreter where necessary.

\subsection{Data Analysis and Interpretation}

Since the methodological approach included literature review and PRA, qualitative analysis was a core method in analyzing data collected. However, house hold surveys and ranking exercises, calendars and timelines generated some quantitative data, which allowed for quantitative comparisons. Secondary data, in the form of reports provided by government departments, provided a combination of quantitative and qualitative information, and an important part of the analysis was to compare the information gathered from stakeholders with the information contained in secondary documents.

\section{The Results of the Study}

The findings presented in this section are based primarily on data collected from a sample of male and female respondents from the project sites. Quantitative data was collected from 443 individuals through a household survey covering the 8 project sites in the two districts of central province. Supplementary quantitative data was also collected from relevant secondary sources including project documents. Also presented here are views from both primary and secondary stakeholders through 8 Focus Group Discussions (FGDs) and 16 Key Informant Interviews.

\subsection{The Communities Livelihood Situation and Forest Resources}

Based on the literature and primary data: from the assessment and focusing on the study objectives. The analysis determined the project sites livelihood and forest resources conservation situation.

\subsubsection{Respondents' Background Characteristics}

Out of 443 respondents who participated in the household survey 237 were female and 205 male. The mean age of these individuals was 42.2 years. The mean household size was found to be 7(6.7) people per house. Overall, majority 64.9 percent of all respondents' household heads had attained primary level education while only 8.1 percent had no formal education. While Majority of the house holds $81.4 \%$ were married.

Table 1. Percent distribution of respondents by age, sex, size, level of education and marital status

\begin{tabular}{llll}
\hline Characteristic $(\mathrm{n}=443)$ & Description & Frequency $(\mathrm{n})$ & Percentage $(\%)$ \\
\hline Average age of the household head & Mean Age $(42.4)$ & & \\
Average household size & Mean household size (6.9) & & \\
Sex of the respondent & Male & 205 & 46.4 \\
& Female & 237 & 53.6 \\
Education & No formal education & 36 & 8.1 \\
& Primary & 287 & 64.9 \\
& Secondary & 115 & 26.0 \\
& Tertiary & 4 & 0.9
\end{tabular}




\begin{tabular}{llll} 
Marital Status of household head & Single/ never married & 5 & 1.1 \\
& Married & 360 & 81.4 \\
& Divorced/separated & 31 & 7.0 \\
& Widowed & 46 & 10.4 \\
\hline
\end{tabular}

\subsubsection{Occupation and Income}

Distribution by type of occupation shows that over 96.6 percent of the respondents were engaged in farming while other occupation included livestock keeping and trading. Majority of the respondents indicated that their approximate total income is less than 1000 kwacha per month. It is also evident that majority of the respondents do not have 'other' sources of income as only 14.3 percent are receiving financial support from external sources (relatives and remittances).

Table 2. Main Household occupation and approximate total monthly household income

\begin{tabular}{llll}
\hline Main source of HH income & Farming & $\mathbf{4 2 7}$ & $\mathbf{9 6 . 6}$ \\
& Livestock keepers & $\mathbf{1}$ & $\mathbf{0 . 2}$ \\
& Wage employment & $\mathbf{1}$ & $\mathbf{0 . 2}$ \\
& Trading & $\mathbf{4}$ & $\mathbf{0 . 9}$ \\
& Other sources of income & $\mathbf{9}$ & $\mathbf{2 . 0}$ \\
\hline Approximate total monthly & Less than 1000 & 401 & 90.7 \\
HH income & Between 1000-2000 & 37 & 8.4 \\
& Between 2000-5000 & 3 & 7 \\
& Over 10000 & 1 & 2 \\
& & & \\
External financial support $(\mathbf{n}=\mathbf{4 4 2})$ & No of HHs receiving & 63 & 14.3 \\
& Not Receiving & 379 & 85.7 \\
\hline
\end{tabular}

\subsubsection{Household average farm size}

While $40 \%$ had a cultivated farm size which was more than 5ha although during FGDs and KIIs it was established that each household had $10 \mathrm{Ha}$ of land allocated to each household by the traditional administration. This suggests that more than a half of the household land was still under trees.

Table 3. Percent distribution of cultivated farm size

\begin{tabular}{llll}
\hline Household Average farm size & Less than $1 \mathrm{Ha}$ & 40 & 9.0 \\
& $1-3 \mathrm{Ha}$ & 126 & 28.5 \\
& $3-5 \mathrm{Ha}$ & 92 & 20.8 \\
& More than $5 \mathrm{Ha}$ & 177 & 40.0 \\
\hline
\end{tabular}

This may be considered as a characteristic of the central province as was also reported in ILUAII final report (2016) that central province had the highest number of trees in the house hold owned land.

\subsubsection{Type of Farming}

Further analysis of farming activities show 56.6 percent of the respondents were engaged in subsistence crop production and $39.1 \%$ are involved in subsistence mixed farming and only $1.1 \%$ were commercial farmers. An indication that although farming was the main occupation of the respondents' household, most of the farming activities were not optimized therefore significantly affecting the household income and sustainability of the livelihood activity in the project site. 


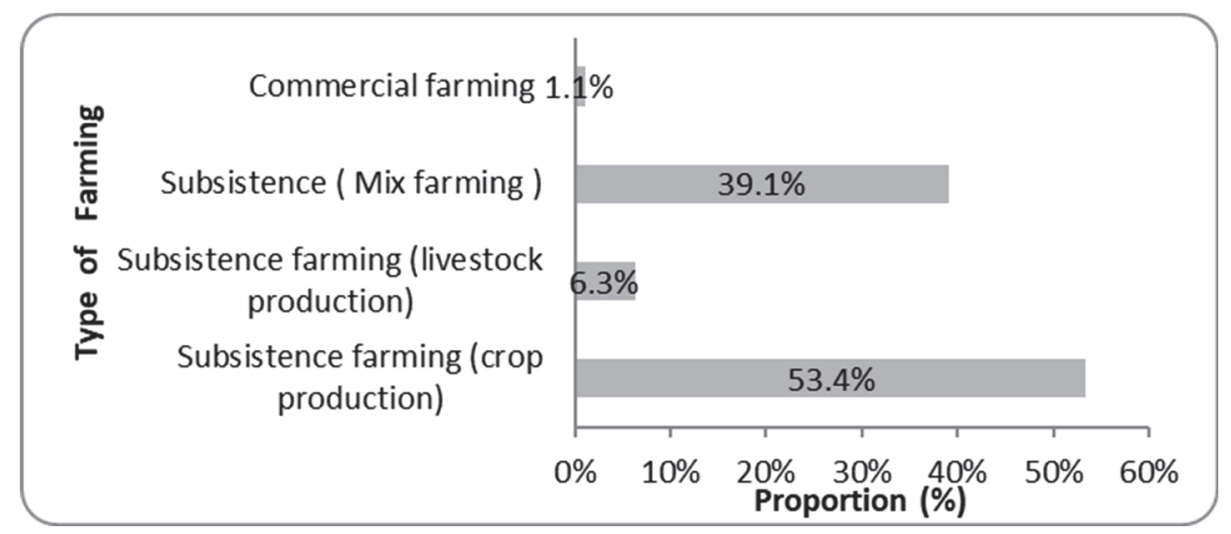

Figure 1. Type of Farming

For example crop-livestock mixed substance systems allow diversification of risks, use labor more efficiently, and recycle crop residues, adding value to crops and crop products while providing cash for purchasing farm inputs. But the households in the study area apart from farming combined a number of livelihood strategies (based on other forest resources) which is consistent with literature on rural livelihoods which report diversification as being predominant (Mamo, et al., 2007)

\subsubsection{Monthly Household Expenditures}

Distribution of respondents by mean monthly household expenditure in Zambian Kwacha indicates that the average monthly spending per household across all items is K 534.49. The highest spending goes towards purchase of food, followed by education, health and transport respectively. The cheapest commodity is fuel with an average mean monthly household expenditure of ZK. 18.37 .

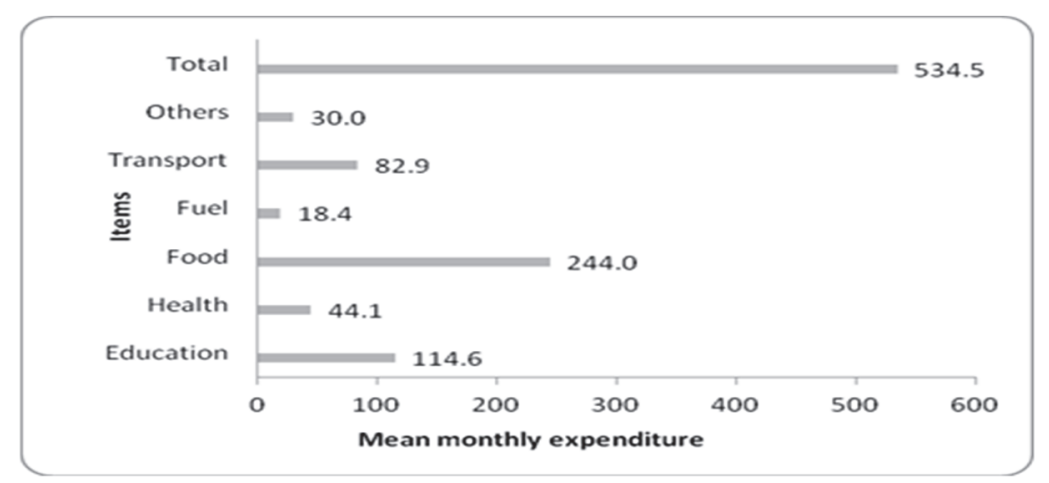

Figure 2. Average monthly expenditures

This shows that although the respondents are mainly practicing subsistence agriculture they still have to purchase food to achieve household food security.

\subsubsection{Food Shortage}

Majority of the respondents (78.1\%) reported that they had experienced food shortage in the last 12 months prior to the survey. Among the respondents who had food shortage the mean of months with shortage was 3.84 . When asked to state their reasons for food shortage, 55.1 percent of the respondents indicated low production as the main reason for food shortage. Another 33.3 percent of respondents reported that their food shortage was due to crop failure. Only 4.1 percent and 5.5 percent of respondents mentioned low off farm income and low trading income respectively as the main reason for experiencing food shortage.

Table 4. Household experiencing food storages, reasons for food shortages

\begin{tabular}{llll}
\hline Characteristic & Description & Frequency (n) & Percentage (\%) \\
\hline
\end{tabular}




\begin{tabular}{|llll}
\hline Food shortage & $\begin{array}{l}\text { Households with food } \\
\text { shortage }\end{array}$ & 345 & 78.1 \\
\hline Period of food shortage & Mean number of months & $(3.84)$ & \\
\hline Reasons for food shortage & & 115 & 33.3 \\
& $\begin{array}{l}\text { Crop failure } \\
\text { Sale of farm produce }\end{array}$ & 7 & 2.0 \\
& $\begin{array}{l}\text { Low off farm income } \\
\text { Low production }\end{array}$ & 14 & 4.1 \\
Low trading income & 190 & 55.1 \\
\hline
\end{tabular}

During the FGDs, participants identified 4 months of food shortages in their calendar (December, January February and March). The FGDs also indicated that NTFPs were the main coping strategy during household food stresses.

\subsubsection{Drinking Water: Source, Distance, Water Payment and Service Provision}

The most common drinking water source was rivers and streams (41.4\%) and 31.7 percent from hand dug wells an indication that majority of the respondents obtained their water from unprotected sources, exposing them to the risk of water borne diseases. But water seems to be within close quarters as majority has water either within their compound (24.9\%) or less than a km away (50.9\%).

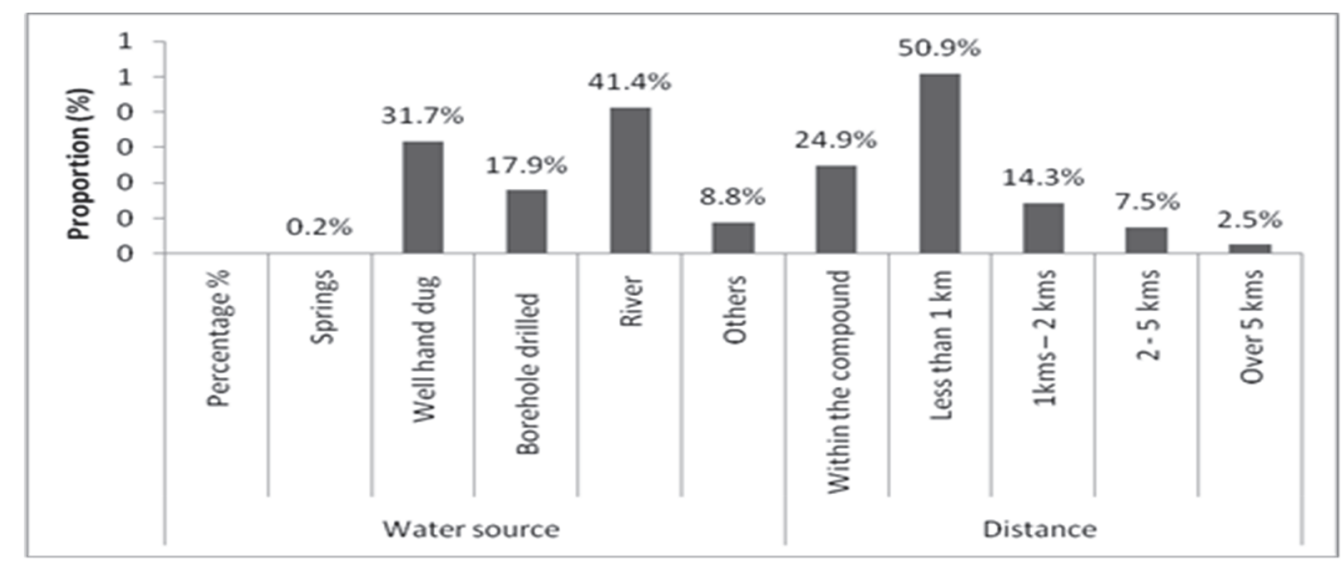

Figure 3. Drinking water source and distance

Findings indicate that over 94 percent of the respondents were not paying for water and 77.4 percent indicated that they had own water sources.

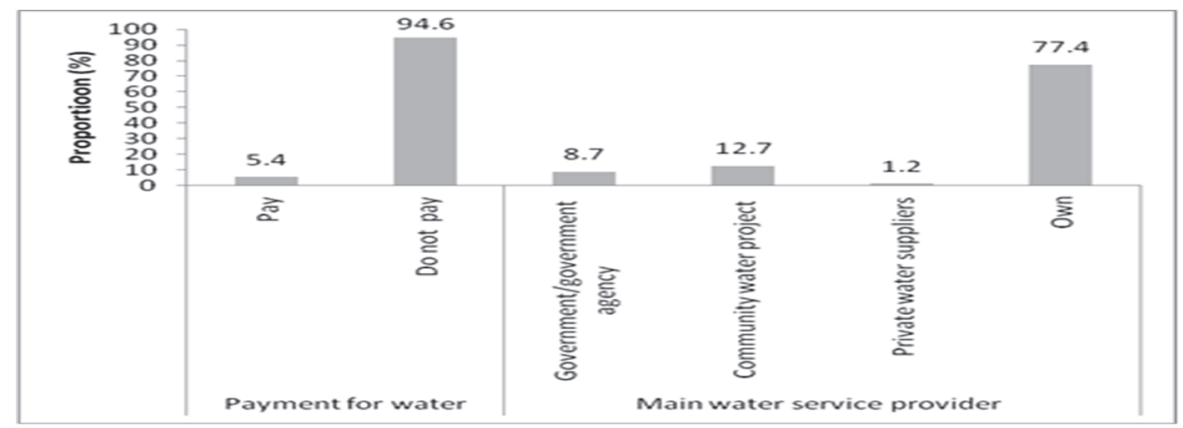

Figure 4. Water payment and service provider

Thus water seems to be treated as a free commodity in the community thus little appreciation of the role the 
resource plays in the sustainability of their livelihood.

\subsubsection{Tree/ Fruit planting}

Majority of the respondents 63.6 percent had not planted any trees or fruits species in the last two years. Only 36.4 percent of the respondent reported that they had planted either a tree or a fruit species in the last 2 years. The most planted tree species was Sesbania sesban while Bananas were the most planted fruit species with a mean of 43.18 and 27.1 respectively.

Table 5. Tree and fruit species planted

\begin{tabular}{lrrlrl}
\hline Tree species & Mean & Rank & Fruit species & \multicolumn{1}{c}{ Mean } & Rank \\
\hline Sesbania sesban & 43.18 & 1 & Mangoes & 9.02 & 2 \\
Cajanas cajan & 27.63 & 4 & Bananas & 27.10 & 1 \\
Tephrosia vogelli & 28.68 & 3 & Pawpaw & 4.40 & 3 \\
Eucalyptus & 36.3 & 2 & Other fruit species & 4.27 & 4 \\
Gmelina aborea & 6 & 5 & & & \\
\hline
\end{tabular}

Lack of planting materials was reported by a majority of the households (40.6 percent) as the main reason for not planting tree species while 41.9 percent have never thought about planting the fruit species. No proper knowledge was reported by 35.9 percent and 32.2 percent of the respondents as reasons for not planting tree and fruit species respectively. Lack of planting materials was reported as the major reason for planting trees while it was the least reason for not planting fruits.

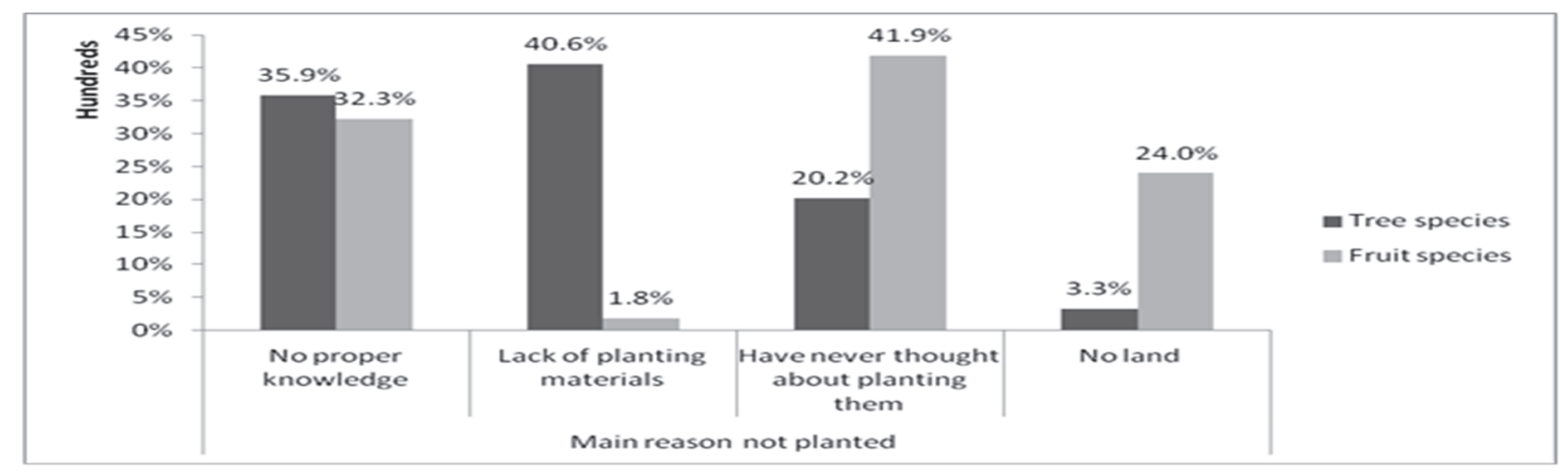

Figure 5. Main reason of not planning trees

3.1.9 Investment undertaken by the respondents in the last two years

When asked on investment undertaken during the last two years the highest investment in capital was construction (26.1\%) followed by business at 15.6 percent while in social investment school fee payment was the most common investment at mean value of K41.2 followed by dowry at mean value of K13.1

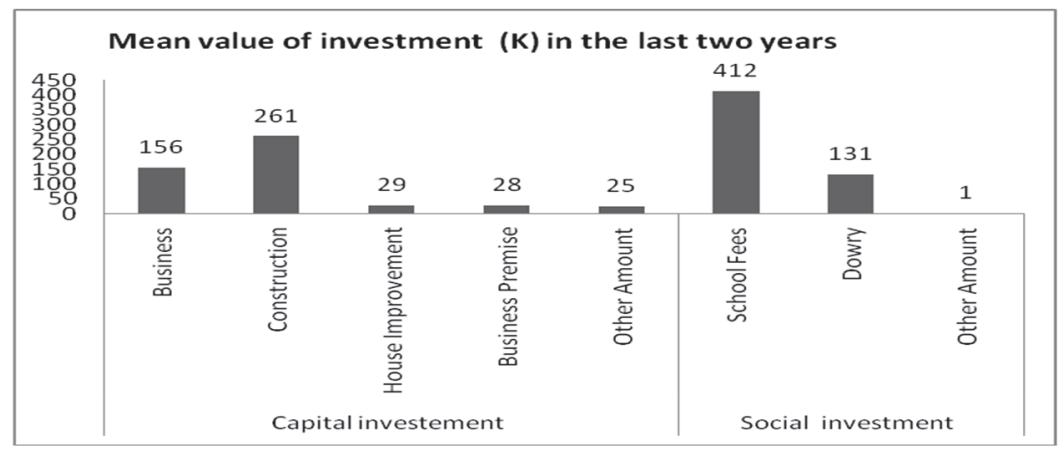

Figure 6. Mean value of investment $(\mathrm{K})$ in the last two years

\subsubsection{Membership to Social Grouping}


When asked if they were members of social group 59.3\% indicated that they belonged to a cooperative but a significant number 24.4 percent indicated that they had no social group

Table 6. The respondents' membership to social grouping

\begin{tabular}{lrr}
\hline & Frequency & Percentage based on respondents \\
\hline Non & 108 & $24.4 \%$ \\
Women/ Men group/ youth group & 33 & $7.5 \%$ \\
Investment group & 2 & $0.5 \%$ \\
Welfare group & 5 & $1.1 \%$ \\
Cooperative society & 262 & $59.3 \%$ \\
Resource user groups & 77 & $17.4 \%$ \\
Total & 442 & $100.0 \%$ \\
\hline
\end{tabular}

3.1.11 Access to formal credits and source of startup capital

The respondents indicated that 63.8 percent had no access to formal credit and 81.8 of those who saved their income was through the traditional banking (under the mattress)

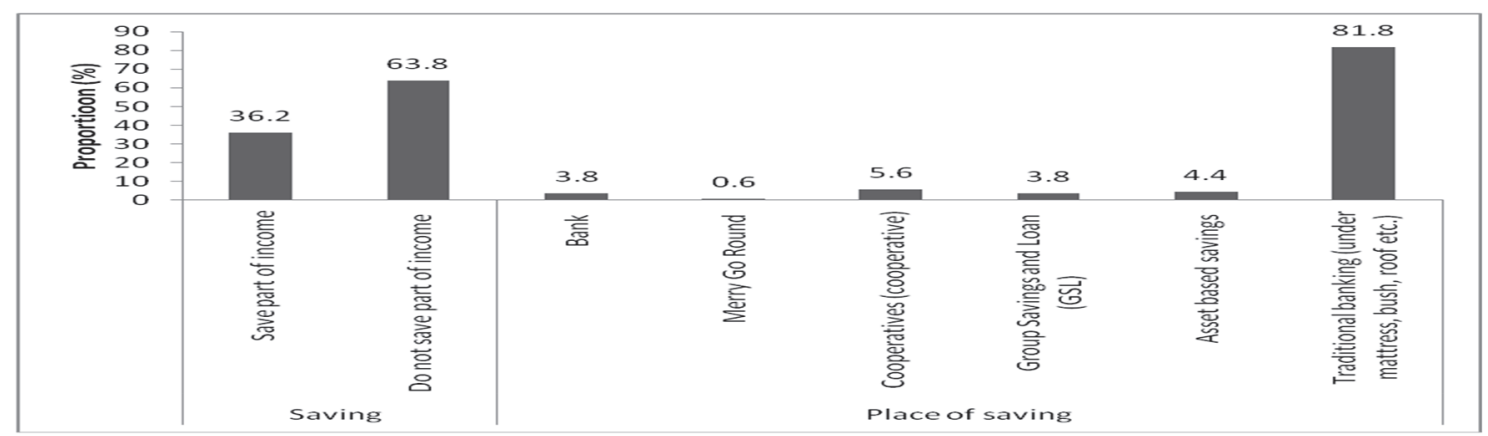

Figure 7. Access to formal credits and source of startup capital

This may be an indication of low levels of asset building and holding as well as inability to attract and therefore to access loans for investment.

\subsubsection{Seasonal Impact and Response Calendar}

The generated seasonal calendar shows the seasonality of livelihood activities and appreciation of when risks were likely to strike in the year and how the respondents coped in a normal year. The results show that the population in the project area was involved in multiple livelihood strategies to obtain sufficient food and income. Crop production was the most important set of activities (land preparation, from planting and harvesting) resulting into a modest harvest. For the poorer groups, the harvest normally runs out in December/January to march, when different types of non-agricultural livelihood activities (collection of caterpillar and mushroom) take over as the main sources of food and income. Livestock sale, although a low leveled livelihood activity occurs throughout the year while fruit collection is continuous depending on the species and season.

Table 7. Respondents seasonal activities calendar

\begin{tabular}{|l|c|c|c|c|c|c|c|c|c|c|c|c|}
\hline ACTIVITY & J & F & M & A & M & J & J & A & S & O & N & D \\
\hline Land preparation for crop cultivation & & & X & X & & & & & & & & \\
\hline Caterpillar harvest & & & & & & & & & & X & X & X \\
\hline Charcoal production & X & X & X & X & X & X & X & X & X & X & X & X \\
\hline Grass collection & & & & & X & X & X & & & & & \\
\hline Livestock sales & L & L & L & L & L & L & L & L & L & L & L & L \\
\hline Food stocks available & L & L & L & & & & & & & & & L \\
\hline Harvesting & & & & & X & X & X & & & & & \\
\hline Planting & & & & & & & & & & & X & X \\
\hline
\end{tabular}




\begin{tabular}{|l|c|c|c|c|c|c|c|c|c|c|c|c|}
\hline Mushroom collection & $\mathbf{X}$ & $\mathbf{X}$ & $\mathbf{X}$ & & & & & & & & $\mathbf{X}$ & $\mathbf{X}$ \\
\hline Collection of wild fruits and nuts & $\mathbf{X}$ & $\mathbf{x}$ & $\mathbf{x}$ & $\mathbf{x}$ & $\mathbf{x}$ & $\mathbf{X}$ & $\mathbf{x}$ & $\mathbf{X}$ & $\mathbf{x}$ & $\mathbf{x}$ & $\mathbf{x}$ & $\mathbf{x}$ \\
\hline Medicine collection & $\mathbf{L}$ & $\mathbf{L}$ & $\mathbf{L}$ & $\mathbf{L}$ & $\mathbf{L}$ & $\mathbf{L}$ & $\mathbf{L}$ & $\mathbf{L}$ & $\mathbf{L}$ & $\mathbf{L}$ & $\mathbf{L}$ & $\mathbf{L}$ \\
\hline Firewood collection & $\mathbf{X}$ & $\mathbf{X}$ & $\mathbf{X}$ & $\mathbf{X}$ & $\mathbf{X}$ & $\mathbf{X}$ & $\mathbf{X}$ & $\mathbf{X}$ & $\mathbf{X}$ & $\mathbf{X}$ & $\mathbf{X}$ & $\mathbf{X}$ \\
\hline Forest fires & & & & & & & & H & H & & & \\
\hline
\end{tabular}

Key: $\mathrm{L}=$ low, $\mathrm{H}=$ high, $\mathrm{X}=$ activity taking place.

Stresses are predictable, continuous and often cumulative (e.g. seasonal food shortages, fluctuations in prices, product glut, trading opportunities etc.), while shocks are sudden and unpredictable (e.g. droughts, floods, crop failure, illnesses and death of household members) and mostly difficult to place in an annual calendar.

\subsubsection{Mitigation and Adaptation Mechanisms}

When asked about the measures they had undertaken to continue accessing forest resources, 68.3 percent of the respondents reported that they had to walk longer distances, and 24.4 percent used different types of resources. Only 3.8 percent and 3.4 percent shifted to new forest area and cultivated or domesticated the resources respectively. The respondents were also asked by the coping measures they had undertaken against declining access to forest or agricultural production only 20.6 percent of the respondents indicated that they had adopted smart agricultural practices while 19.5 percent had undertaken agro forestry technologies. Some 19.5 percent had diversified to non-farm income sources as a coping measure against declining access to forest or agricultural production.

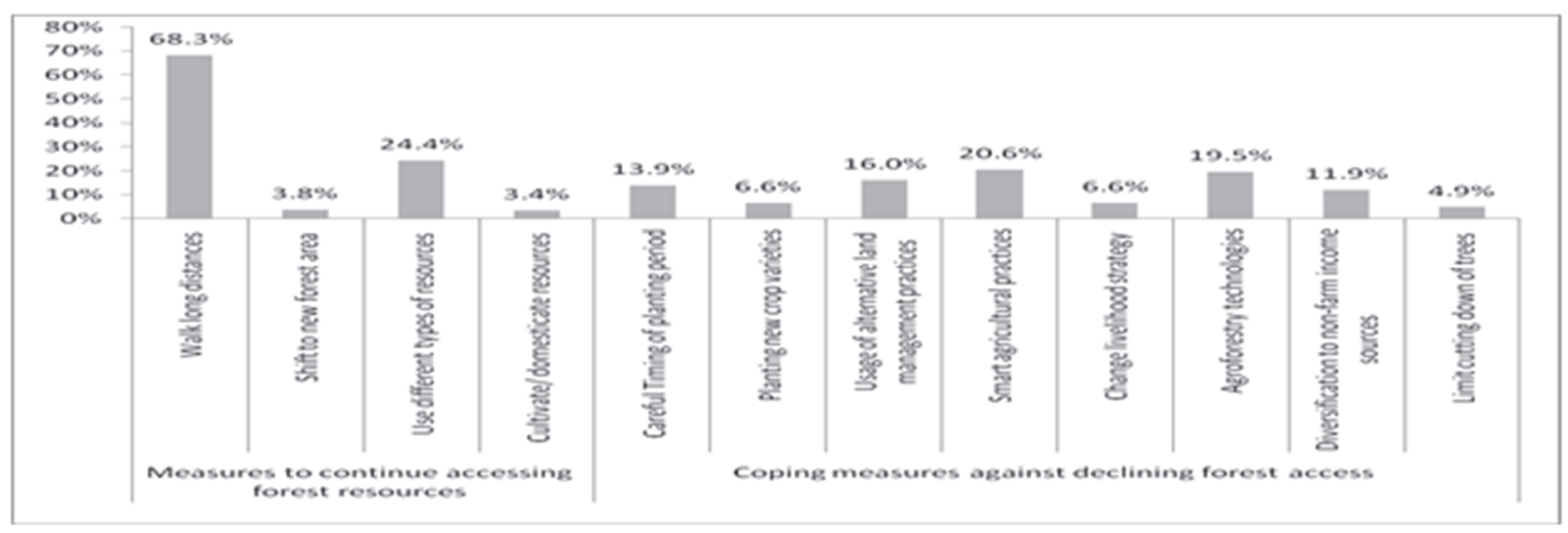

Figure 8. Mitigation and adaptation mechanisms

It was further reported that deforestation had led to households losing revenue which was once realized from sale of mushrooms and fruits. According to a female FGD participants in Nakatambo,

"...We used to have loads of Masuku fruits and mushrooms to sale, now the productivity had drastically reduced...."

\subsubsection{Natural Resource Policy Engagement}

When asked if they were being engaged in policy formulation processes $63.3 \%$ indicated that they were not engaged and among those that were engaged $80 \%$ of the engagement was with national government. 


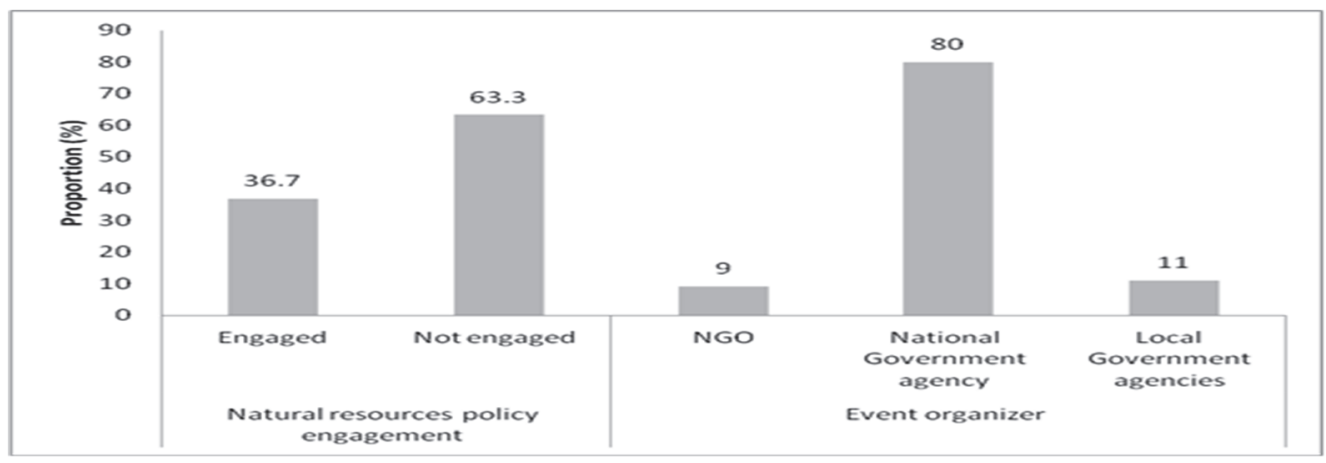

Figure 9. Natural resource policy engagements

Although KIIs indicated that there were rules of engagement for the utilization of forest products, further probing in FGDs showed that the rules were easily flouted. And no protection of trees for a particular environmental or cultural service existed. As reported in an FGD.

“.....When I first migrated to this village, I was observing the customary rules on harvesting of forest products such as fruit trees etc. but I stopped when I realized the other people here were not following any rules....... FDG respondent in London village....

\subsection{Livelihoods in the Project Sites}

Literature suggests that a significant component of the forests in the project sites were heavily modified by intensive use especially due to farming activities: clearing forest for cultivation (FAO 2005).

Local community's main livelihoods were derived from agricultural production (Mainly subsistence crop farming). Crop production apart from ensuring food security, it was also a major source of cash income in these communities; collection of forest products (mushroom, wild fruits, caterpillar and honey) were a good medium term investment. Livestock production was also an important means of medium to long term investment.

According to KIIs and FGDs there is a high dependence (100\%) on the forest resources for their livelihoods. The respondents listed 20 livelihood activities (goods and services) based on the forest and forest resources (see table in appendix 1). When asked to rank: farmland was ranked as the most important resource in terms of its contribution to household income followed by wood fuel, mushrooms and caterpillar respectively.

Table 8. Most important products livelihood ranked in by the respondents in a ranking exercise

\begin{tabular}{lrlr}
\hline Item & Ranking & Item & Ranking \\
\hline Farmland & 1 & $\begin{array}{l}\text { Poles } \\
\text { housing }\end{array}$ & for \\
Fuel wood & & Charcoal & 7 \\
Mushroom & $\mathbf{3}$ & Honey & 8 \\
Caterpillars & & Grazing & 9 \\
Wild fruits & 4 & (livestock) & \\
\hline
\end{tabular}

Households used more than one product with the majority of households reporting being engaged in collection of wild fruits (81.7\%) mushrooms (87.5\%), poles for construction (53.4\%) and honey (20.5\%). All Respondents had crop fields and the crop cultivated included: Maize, finger millet, cassava, sweet potatoes bean and groundnuts although the crop yield and eventual income was reported as low. The challenges cited by the respondents included

- Small capital input

- Poor farming methods

- Low farm input usage e.g. (fertilizer, and certified seeds).

- high cost of transportation, 
- fluctuated price,

- Seasonal rainfall variability

- Diseases and pesticide

- Over cultivated land

Farm yields were reported as declining $(88.2 \%)$ and increased demand for more land for cultivation. This indicates a risk to the livelihood and conservation thus need for intervention.

Table 9. Changes faced in agriculture in the last two years

\begin{tabular}{|c|c|c|}
\hline $\begin{array}{c}\text { changes faced in agriculture in the } \\
\text { past two years }\end{array}$ & $\begin{array}{c}\text { Number of times the aspect was } \\
\text { mentioned (f) }\end{array}$ & $\begin{array}{c}\text { Percentage based on } \\
\text { respondents \% }\end{array}$ \\
\hline No Noticeable change & 58 & 13.2 \\
\hline Low yields & 387 & 88.2 \\
\hline un timely rains & 188 & 42.8 \\
\hline Lower rains & 189 & 43.1 \\
\hline Very high amounts of rainfall & 17 & 3.2 \\
\hline Extended dry seasons & 56 & 12.8 \\
\hline New diseases and pests & 126 & 28.7 \\
\hline Others specify & 49 & 11.2 \\
\hline
\end{tabular}

Moreover, the market in the project sites had not developed; thus, products only reach customers after going through several middle actors thus a need to develop a marketing platform in order to solve the problem.

Livestock production based on a free-range approach (village chicken, pigs, goats and cattle) although identified as a key livelihood activity, a popular asset accumulation source and provider of draught power in some instances for land preparation. This livelihood activity is relatively low in the study area signified by farmers having very few animals (most farmers had less than 10 units per animal type) and poor technological knowhow in the subsector. The challenges cited by the respondents included

- Small capital input

- Poor livestock production methods

- Inadequate feed

- Diseases and pesticide

- Conflict between crop production and livestock (animals destroying crop fields)

None issuing of titles for forest and community land was inhibiting local farmers from investing in land rehabilitation such as planting trees etc., which has a negative impact on their livelihoods and the environment. Distributing land to individual households although increased household income, created conflicts over rights to forest land. Several households illegally encroached into forest land with permission from the traditional chiefdom system.

A number of other studies have also shown that income from forests is important to rural livelihoods than previously perceived (Arnold and Townson, 1998). Almost 100\% of farmer households access community or protected forest land to collection of Mushrooms, Caterpillar and wild fruits in the study area. Honey production is a relatively new and a potential income source. The key forest products mentioned include:

\subsubsection{Livelihood Based on Forest Wood Products}

From a conventional forester's perspective, the type of the forest in project area (miombo woodland) fundamentally supports relatively few good commercial timber species, except in a few areas and the remaining commercially viable stocks are relatively few as also mentioned in Richardson et al., (2015). Therefore wood products were mainly extracted from the forest for use as fuelwood, for charcoal production, construction materials/poles and in limited instances production of timber (Mapulanga). Fuelwood was the main primary sources of energy for domestic use and accounts for high percentages of the total household energy requirements especially for cooking.

Table 10. Respondents main source of energy for cooking 


\begin{tabular}{|l|r|r|}
\hline \multicolumn{3}{|c|}{ Cooking } \\
\hline Source & Frequency & Percent (\%) \\
\hline Firewood & 434 & 98.2 \\
\hline Charcoal & 7 & 1.8 \\
\hline Total (N) & 442 & 100 \\
\hline
\end{tabular}

Commercial harvesting of forest trees for charcoal overrides patterns from other harvesting purposes because of economic incentive and the wide range of species and size classes harvested. Charcoal was identified as an important source of cash income for the household, during FGDs however the importance was down played as most of the community members considered it as an illegal activity and did not want to be associated with it. There was a well-established charcoal trade network from rural areas to urban areas, especially in Teta and Kampabwa where it was reported that there were manganese factories that used charcoal as the main energy source, consequently, a well-established markets. But KIIs indicated that the manganese factories had recently changed to using other sources of energy and thus charcoal production had gone down thus a recent reduction on the commercial demand for charcoal in the area.

Charcoal production as a livelihood activity was characterized with use of inefficient production technology from the supply side and inefficient cooking stove type from the demand side thus a need for interventions. Fuelwood and charcoal consumption combined with slash and burn agriculture has accelerated forest degradation in the project site.

\subsubsection{Livelihood based on Non-Timber Forest Products (NTFPs)}

The results show that there is a tradition and increasing emphasis on the contribution of NTFPs to the livelihoods of communities living adjacent to the forests and a need for sustainable management of forest ecosystems to ensure the continued availability of these NTFPs.

Households sell various NTFPs (90 percent of the sampled households sold more than one product) that contribute to the household income, therefore a diversified economic portfolio. Mushrooms, wild fruits and caterpillars were the main NTFPs considered as sources of income. Therefore NTFPs provided a range of products for subsistence consumption and trade. Others include, honey products, medicinal plants, munkoyo (traditional drink made from maize or sorghum but fermented using some specific tubers from the forest) and bush meats were some of the listed items. Over the years, there has been an increase in reliance on NTFPs for a large number of people due to high incidence of poverty and the limited access to products and services from the formal sector (FAO, 2005). Additionally, the growing international trade in a number of products has increased their demand.

Previous studies indicates that for most users the importance of forest products income is mainly to fill gaps and compliment other income sources, than in its absolute magnitude or share of average household income. And forest products tend to be especially crucial to poor rural households in periods of hardship, as forest foods often become one of households' main sources of sustenance, particularly for women and children (Kaimowitz, 2003).

The key items are discussed below.

\section{i) Wild Fruits and Nuts}

The utilization of wild fruits and nuts is an important livelihood activity. Wild fruits are of great importance in the diet of many of the respondents. Fruit sale was also a strategy to meet specific cash income. The respondents indicated that they have witnessed increased interest in the conservation and domestication efforts of indigenous wild fruit trees. The wild fruits commonly mentioned in the project site included Mpunda, Masuku and Tusongole etc.

Harvesting wild fruits from the forest and semi-domesticated trees growing on-farm may substantially boost rural income and create employment, especially with processing and value addition. There is need for an intensive participatory domestication capacity building and research using local and national partners. This may create opportunities for the development of the indigenous fruit trees as new crops and their management. Thus a winwin strategy aimed at reducing overdependence and exploitation of the wild population, while at the same time helping farmers to develop new tree crops to enhance economic opportunities.

\section{ii). Mushrooms}

In all FGDs mushroom collection was ranked as one of the top five most important livelihoods in the project sites. 
Although the quantities and market values are not known, mushrooms are widely collected and traded by the local populations.

Harvesting mushroom from the forest and on-farm substantially enhances the household income and may create employment, especially with processing and value addition. There is need for an intensive participatory domestication capacity building and research using local and national partners. This may create opportunities for the development of the mushroom sub sector.

\section{iii). Edible insects (Caterpillar)}

The most common insects were edible caterpillars (Chidumayo and Mbata, 2002). According to the FGDs, the caterpillars were not only a source of food but also a source of income enabling local people to buy goods and services that otherwise would not be obtained. Hence, collection and trade in edible caterpillars is widespread in the project area. It's an important livelihood activity in November and December when caterpillars are collected mostly from regenerating woodlands that had previously been cleared and burnt. In some cases participants indicated that people travel up to $200-300 \mathrm{~km}$ to pick caterpillars, and traders travel up to $500 \mathrm{~km}$ (from Lusaka) to buy them. Reports from previous studies show that utilization of caterpillars is a viable enterprise for rural communities in Zambia (Chirwa, et al., 2008). Even in years of moderate abundance, edible caterpillars generate incomes of over US\$ 60 per household that are comparable or even higher than incomes from sales of some agricultural crops in central Zambia ( Syampungani et al., 2009)

The methods of harvesting edible caterpillars at times contributed to deforestation. Forestry Department in Zambia considered the caterpillars as pests due to the damage done by people collecting them illegally in the National Forests, using forest fires to create conducive habitat for their breeding. During FGDs the participants indicated that major causes of decline of edible caterpillar populations included deforestation, forest fires and overgrazing.

\section{iv). Honey}

Honey hunting and traditional beekeeping have long been part of the subsistence economy of the population in the project area. Honey-hunting from undomesticated colonies of bees is done by several house hold on an opportunistic basis, while beekeeping is often a specialist enterprise. In the project sites, honey hunting and beekeeping was an important source of income for the households. Management of the hives and colonies was adapted to the seasonal nature of the woodlands and the semi-migratory habits of the bees. Hence traditional beekeeping worked within a framework set by the subsistence needs of the household, the chance to earn supplementary income, and the opportunity of supplying important commodities to the community to the enhancement of social relationships.

Beekeeping was for a long time considered detrimental to forestry, because of the large number of trees used in hive construction, and the indiscriminate burning that was sometimes caused by honey-hunters. However, if modern hives are promoted, beekeeping may be carried out in the forest with limited conflicts with any other form of land use.

\section{v). Medicinal Plants}

In the study area a significant population uses traditional medicines for their primary healthcare needs. The range of health products has increased both within and outside the project area. Thus various medicinal plants deserve special attention, not only in view of their importance in traditional healing, but also for their contribution to expenditure on health for the households. As well as being a potential trading commodity. There is inadequacy of conventional medicinal facilities creating growing demand for traditional healing which in turn increases the demand and economic potential for medicinal plants.

Trade in medicinal plant products can greatly enhance the economic well-being of communities at local, national and international levels. The informal trade of medicinal plants and products may be dominated by traditional healers that dispense medicines and herbal remedies. Local communities have exploited the leaves for treating several ailments, such as constipation, toothache, cold and cough, fever, pains, measles and malaria. Because of unsustainable harvesting methods and economic pressures, medicinal trees may be threatened.

\section{Vii) Bush Meat and Other Animal Products}

Wildlife in form of fauna was an important source of food (proteins) in the project area. The fauna was in the form of, mice, and reptile and bush meat /or bird eggs. Consumptive utilization of fauna involves hunting for subsistence. The levels of and, dependence on game in the project area is not well documented. But the area is depleted of game populations suggesting over-exploitation.

\subsection{Proposed Sustainable Livelihood Activities Using the Local Knowledge}


Many case studies across the country and the region show that dependence on subsistence agriculture and subsistence utilization of forest resources has basically failed in improving the living standards of local communities and is notorious for degrading the forest resources. But a wide range of products still played a significant contribution to the total household livelihood among the forest communities (Kalaba et al., 2012). Therefore promotion of alternative livelihoods and economic incentives based on prudent natural resources management that integrate local knowledge and biological conservation with economic development is needed for sustainable livelihoods. More specifically opportunities based on mid and small-scale trades in forest resources need to be explored. The proposed sustainable livelihood activities include the following:

\section{Commercialization of NTFPs based on Fair Trade Principles}

Although the value of NTFPs for the local and national economy is not well documented, many studies propose that NTFPs be mainstreamed into the local and national economies as a pathway for enhancing household livelihoods by collecting, processing and marketing NTFPs. Small scale harvesting of NTFPs has a relatively low impact on the environment but it is important that the commercialization is guarded; because where NTFPs increase in value more influential actors may emerge to control the resources and/or the market resulting in negative social and environmental impacts. Commercialization may also intensify management of the resource stimulated by increased demand leading to domestication of particular plants regarded as highvalue forest products therefore a need to revisit both local and regional policies governing the management of NTFPs to facilitate sustainable resource management through improved access to the resource and provision of improved technology and information on markets. Examples of NTFPs commercialization include: i) promotion of mass-production methods for edible caterpillars just like silkworms production. This may also result into reducing the destructive caterpillar harvesting methods currently employed. ii) Promotion of mushroom production and iii) production of wild fruits, leafy vegetables and tubers

Similar studies by Akinnifesi et al. (2008) show that other factors favoring the commercialization of NTFPs include: trends in food markets, with growing emphasis on variety and organic products. NTFPs may qualify as organic products, especially if operated within fair trade principles. The opportunities presented by these emerging markets may greatly benefit the locals and conservation. The strategy must embrace issues related to supply chain such as, quality assurance and pricing. The producers may require training in marketing and an effective market information platform (such as cooperatives etc.).

\section{Sustainable Energy/Charcoal Production}

Unless a significant shift in the national energy policy direction is achieved in Zambia there are expanding domestic markets and new emerging market trends for charcoal. Increasing urbanization have greatly increased the demand for charcoal, persistently low income urban population continues to provide a strong growth in urban consumption of charcoal and firewood. To reduce dependence on fuelwood extraction and charcoal burning, the following need consideration: (1) promotion of agroforestry practices for production of fuelwood (2) promotion of on-farm alternative biomass energy sources (3) design of improved stoves and promotion of efficient kilns for charcoal production, (3) promote energy policies specifically focused on biomass production, and (4) encouragement of other alternative and renewable energy sources such as solar, wind and biogas.

There have been previous interventions in the two districts aimed at promoting sustainable charcoal production and utilization technologies or alternative energy sources. An NGO, Green Living movement had promoted establishment of fuel woodlots among local farmers

\section{Sustainable Bee Keeping for Honey and Associated Products}

To reduce dependence on honey-hunting and tree-debarking, improved beekeeping using appropriate technologies need to be promoted. A local NGO Community Markets for Conservation (COMACO) has been working with the District beekeeping association to promote beekeeping. There are also opportunities for integration of beekeeping and edible caterpillar collection.

\section{Agroforestry and Conservation Agriculture}

Agricultural techniques that conserve biomass and build soil organic matter, such as agroforestry, resulted in a landscape that is both agriculturally productive thus enhance the farmer's livelihood and rich in carbon. Sustainable intensification interventions on the other hand have the potential to mitigate the impact of agriculture on the landscape by intensifying agricultural production without increasing deforestation or the cultivation of more land and without reducing biodiversity.

Agroforestry and conservation agriculture are practiced on a small scale in the two districts with the assistance 
of the Conservation Farming Unit (CFU) and Development Aid from People to People (DAPP). The main species promoted include Faidherbia albidia, Sesbania sesban and Tephrosia vogelli for soil fertility improvement. Green Forest Movement has also been promoting the establishment of eucalyptus plantations in degraded land areas.

\subsection{Identify and Recommend Other Sustainable Livelihood Practices}

The relationship between changing trends in forestry management globally and forestry related environmental services has been central to innovative utilization of the resource, funding and promotion of markets for environmental services (MES). Forests are considered as vital natural resources providing ecosystem services including: landscapes scenery, biodiversity conservation, carbon sequestration, wildlife habitats and watershed protection. Sustainable forest Livelihoods options should likewise consider these aspects. It is a form of nonconsumptive use of the forest resources and hence a well suited element for conservation of the forest and its biodiversity as well as enhancing livelihood. Recommendable sustainable Livelihood practices include:

\section{Payment for Ecosystems Services (PES) Based Livelihood Activities}

PES is suggested as a strategy to bridge the perceived disconnect between environmental conservation and sustainable livelihood. The Interest in the idea of paying others, such as communities on forested land, to provide environmental services on a sustained basis, is a growing concept. PES has the potential to provide important additional and regular income flows, or other material benefits, for forest-dwelling communities. These ecosystem services based livelihood activities include.

Woodland managed for carbon sequestration: These are Land-use projects that create carbon sinks (i.e., resulting in the net uptake of $\mathrm{CO} 2$ from the atmosphere) or prevent carbon generation sources therefore contributing to carbon emission reduction. The contribution of carbon sequestration projects to the well-being of the communities around the forests/woodlands are well documented in the region including in Tanzania and Uganda.

ii) Eco-tourism may be considered as an alternative source of income and livelihood that can divert local communities away from actions that negatively impact the Forest. A well designed eco-tourism programme offers potential to enable local residents to receive substantial economic benefits while simultaneously creating incentives for forest conservation. Examples include game farming as an alternative way of managing wildlife resource to derive benefits for both government and the local communities. Documented eco-tourism successes include Kipepeo project in Kenya and Zimbabwe etc. Wildlife management schemes which display features of PES have been relatively successful in the region.

iii) Extended carbon storage management projects: carbon storage benefits of forest may be extension beyond 50 years by harvesting the timber sustainably and converting it to long-lived products such as furniture etc. This has the potential to enable the local population to receive substantial economic benefits while simultaneously creating innovative products for unique but emerging markets.

iv) Promotion of natural woodland regeneration projects: through coppice or regeneration management. Thus averting degradation and deforestation. The forest type in the project site is documented as one that actually regenerates fairly easily and prolifically, provided that regeneration is not inhibited by late dry season fires or by cultivation.

v) Fire management designed in a PES model: prudent fire management initiatives may cause reduction in fire frequency in the woodlands thus increase carbon uptake for photosynthetic activities.

\subsection{Proposed Mechanisms to Support the Recommended Best Practices}

This assessment indicates that currently there are Low margins and shallow markets for the forest products that promise sustainable livelihood and thus limit the potential for improving incomes from better management of the resources. The obvious markets are neither easily accessible nor well developed. Thus without mechanisms for developing these markets, the products offer minimal paths to sustainable livelihood. A combination of factors including: the complexity of managing such woodland for multiple products, low margins and weak markets, weak local institutions, and inadequately informed policies, has already resulted into a high rate of forest degradation in Zambia as recorded in various reports. These factors may help us identify the points of entry for mechanisms that may support the recommended best practices specifically in the project area and in Zambia in general.

1. Reorient and Capacity build Institutions mandated to manage Forests to strengthen the Decentralization Agenda: the silviculture of managing these forest ecosystems seems complex especially when multiple stakeholders have different interests and outcomes. KIIs and literature reviews indicate that the management of forests in the project sites is devolved, where local institutions (traditional 
chiefdoms) manage the resource. Mostly, the rights to use and access the woodland resources especially the community forests remain with the traditional chiefdom system. The regulatory framework is such that it is easy to be illegal without being punished and often expires little more than the interest of the individual local chiefdom rather than the national or local forest administration priority.

While many of the government protected forest areas as well as the community forests were established when population pressures were low, and simply "reserving" these areas was adequate to maintain them. As population pressures increased, forest departments and local chiefdom administrations seem to be unequipped with adequate forest management mechanisms in place thus not responsive to new needs for management. The local administration either exploits what they perceived to be a "free" resource or the forests are proving to be victims of 'tragedy of the commons' where the government has given the customary authorities control over natural resources which far exceeds their capacity for management. For example the by-laws regulating bush fires and the opening and closing dates of caterpillar collection are enforced by the chiefs but seems to be poorly implemented.

There is need to capacity build and ensuring that these grass root organizations put in place effective management mechanisms. This organization includes, District Development Coordinating Committee (DDCC), Community Resource Boards (CRBs). The Village Resource Management Committees (VRMCs) and Village Action Groups (VAGs).

2. Enhanced Policy Legal and Institutional Arrangements: if policies have to be effective, they need to be inclusive by taking all stakeholders on board and providing an opportunity for stakeholders to meet their needs as they contribute towards sustainable forest management. This approach recognizes the vital role that local communities play in forest management. The formulation of participatory forest management policies. Participatory forest management has been practiced in many parts of Sub-Saharan Africa: Burkina Faso; Cameroon; Ghana etc.

Policies conducive to promotion of small- scale, more sustainable technologies such as alternative (clean) energy development and agroforestry are lacking. Programs and policies which take into account the complex economic forces that influence energy production and consumption are urgently needed. It is therefore important that forestry and energy policies are complementary in order to foster the achievement of maximum benefits which the forest has to offer. Additionally, the promotion of more efficient wood stoves and the development of more modern production systems such as the use of wood for electricity production may contribute towards sustainable forest management.

3. Establishment of Producer and Trade Associations: will prove a much needed incentive for better management of the forest resources, including simplification of the regulatory regime to reduce transaction costs for poor producers, and developing a framework for providing greater support for producer organizations and user groups. Establishment of trade associations will ensure the promotion of market diversification, in improving the prospects for niche market entry, and in establishing product standards.

4. Revitalizing the Forestry Department: most government departments are generally underfunded and not aligned with the major thrusts of rural development efforts. There is also much resistance to change, even though a failure to adapt increases their marginalization. Perhaps the biggest challenge for the forest department is the reorientation from their earlier roles, which were largely regulatory, to roles which have a much stronger service-delivery orientation, aligned with the sustainable livelihood agenda. On the other hand it may be that the current roles of the forest department need to be reduced to focus on a few strategic themes, and the wider responsibilities for service delivery be undertaken by other institutions in the subsector with greater capacity for engaging local stakeholders in improving natural resource management.

5. Incorporate Ecological Aspects of Forest in Development Planning: commercialization is always associated with disastrous effects on the environment, as attested to by the rampant deforestation that has been caused by charcoal production in the project area. Similarly Harvesting of NTFP in some cases entails practices that curtail the biological performance of the plants such as whole stem girdling in bark harvesting etc. But studies that link commercialization of NTFPs and the ecology of a particular system are limited due to the complex nature of the causal-effect relationship of the two. In some cases, harvesting can actually improve the productivity of individual members of a species or of a forest ecosystem. On the other hand, many wild populations exhibit a great degree of variability and unpredictability in resource productivity due to seasonality, forest type and even among individuals of 
the same species. These properties may result into the commercial use of wild populations an unreliable source of income for local populations and a high-risk venture for private capital.

\section{Recommendation and Conclusions}

\subsection{Conclusions}

Forests play a central role in rural livelihoods in the project sites, and have high potential to provide sustainable livelihood among rural populations, by enabling significant income generation, mobilization of savings, capital accumulation, and asset-building. This is mainly constrained by the factors that characterize the communities, including low levels of education, low levels of asset holding, weak local institutions and unfavorable legal and institutional frameworks. Much of the evidence suggests that sustained economic gains for the majority of forest dependent rural populations will require broader macro-level investments beyond forests and natural resources. Multi-scale, integrated and holistic development approaches targeting, Non Timber Forest products and Services (NTFPS) value addition will be needed to achieve sustainable livelihood and forest conservation. A range of specifically forest sector elements would also need to be addressed, including market and skill development for forest product and services delivery; development and integration of and reorientation of energy policies into the forest sector and increased competitiveness of the NTFPS in general. Embracing these elements will also require new types and enhanced institutional arrangements.

\subsection{Recommendations}

Key policy related thrusts need to be:

i. Strengthen resources rights of the poor

ii. Enhance the capacity of the rural population to manage the environment

iii. Increase the use of environmental valuation

iv. Improve uniformity of policy application and resolution of cross-sectoral issues and responsibilities

v. Improve capacity development of the forest department staff, Natural resources management committees and the Village Action Groups (VAGS)

vi. Support existing small-scale entrepreneurs with respect to business and marketing skills

vii. Design and implement pro poor resource access and sustainable harvesting programmes

\section{References}

Akinnifesi, F. K., Kwesiga, F. R., Mhango, J., Chilanga, T., Mkonda, A., Kadu, C. A. C., ... Dhliwayo, P. (2006). Towards the development of Miombo fruit trees as commercial tree crops in southern Africa. Forests, Trees and Livelihoods, 16, 103-121.

Akinnifesi, F. K., Sileshi, G., Ajayi, O. C., Chirwa, P. W., Kwesiga, F., \& Harawa, R. (2008). Contributions of agroforestry research and development to livelihood of smallholder farmers in southern Africa: 2. Fruit, medicinal, fuelwood and fodder tree systems. Agricultural Journal, 3, 76-88. Campbell et al., 2008.

Alexiades, M. N., \& Shanley, P. (2005). (Ed)Forest Products, Livelihoods and Conservation Case Studies of NonTimber Forest Product Systems VOLUME 3 - LATIN AMERICA SMK Grafika Desa Putera, Indonesia ISBN 979-3361-24-7

Arnold, J. E. M., \& Townson, I. (1998). Assessing the Potential of Forest Product Activities to Contribute to Rural Incomes in Africa. ODI Natural Resource Perspectives, No 37, November.

Catherine, M., Greg, B., Niall, C., \& Lucy, B. (2015). The sustainable livelihoods Handbook An asset based approach to poverty. from www.church-poverty.org.uk

Chidumayo, E. N., \& Mbata, K. J. (2002). Shifting cultivation, edible caterpillars and livelihoods in the Kopa area of northern Zambia. Forests. Trees and Livelihoods, 12, 175-193.

Chirwa, P. W., Akinnifesi, F. K., Sileshi, G., Syampungani, S., Kalaba, F. K., \& Ajayi, O. C. (2008). Opportunity for conserving and utilizing agrobiodiversity through agroforestry in Southern Africa. Biodiversity, 9, 45-48.

FAO (2005). Forestry outlook study for Africa: subregional report southern Africa. African Development Bank/European Commission/Food and Agriculture Organization of the United Nations, Rome.

FAO (2014). Forest Livelihood and Economic Survey (FLES) of the Integrated Land Use Assessment Ii Data Collection Manual Republic of Zambia Ministry of Lands, Natural Resources and Environmental Protection: Forestry Department Central Statistical Office. 
GRZ (2006). Annual report of the Forestry Department 2006. Ministry of Tourism, Environment and Natural Resources. Lusaka: Government Printers.

GRZ (2014). Forest Livelihood and Economic Survey (FLES).

Jayne, T. S., Chamberlin, J., \& Headey, D. (2014). Land Pressures, the evolution of farming systems, and development strategies in Africa: a synthesis. Food Policy, 48, 1-17.

Kaimowitz, D. (2003). Not by bread alone: Forests and Rural Livelihoods in Sub-Saharan Africa. In T. Oksanen, B. Pajari and T. Tuomasjukka (eds.), Forests in poverty reduction strategies: capturing the potential. EFI Proceedings No 47. European Forest Institute, Joensuu. Pp. 45-63.

Kalaba, F. K., Quinn, C. H., \& Dougil A. J. 1. (2012). Contribution of forest provisioning ecosystem services to rural livelihoods in Copperbelt's Miombo woodlands, Zambia. Sustainability Research Institute (SRI), School of Earth and Environment, the University of Leeds, Leeds, LS2 9JT, United Kingdom.

Kalinda, T., \& Bwalya, S. M. (2014). Utilization of forest products and services for livelihoods among households in Zambia. Research Journal for Environmental and Earth Sciences, 6(2), 102-111.

Kalinda, T., Bwalya, S., Munkosha, J., \& Siampale, A. (2013). An Appraisal of Forest Resources in Zambia Using the Integrated Land Use Assessment (ILUA) Survey Data. Research Journal of Environmental and Earth Sciences, 5(10), 619-630.

Mamo, G., Sjaastad, E., \& Vedeld, P. (2007). Economic dependence on forest resources: A case from Dendi district, Ethiopia. Forest Policy and Economics, 9, 916-927.

Ministry for Foreign Affairs of Finland. Country Strategy for Development Cooperation with ZAMBIA 20142017

Richardson, R. B., Olabisi L. S., Sakana N., Waldman K., \& Grabowski, P. (2015) The impact of sustainable intensification on landscapes and livelihoods (SILL) in Zambia International Institute of Tropical Agriculture www.africa-rising.net.

Syampungani, S., Chirwa, P. W., Akinnifesi, F. K., Sileshi G., \& Oluyede, C. A. (2009). The miombo woodlands at the cross roads: Potential threats, sustainable livelihoods, policy gaps and challenges. Natural Resources Forum, 33, 150-159.

\section{Copyrights}

Copyright for this article is retained by the author(s), with first publication rights granted to the journal.

This is an open-access article distributed under the terms and conditions of the Creative Commons Attribution license (http://creativecommons.org/licenses/by/4.0/). 